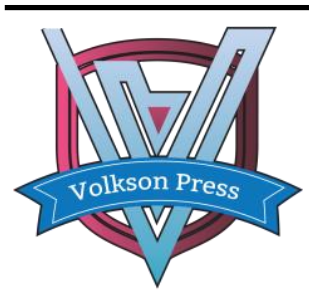

Contents List available at VOLKSON PRESS

Engineering \& Technology Innovations (ETI)

DOI : http://doi.org/10.26480/iceti.01.2017.33.36

\title{
NOVEL SULFO FATTY ACID FOR FLOTATION SEPARATION OF CARBONATES AGAINST PHOSPHATE ROCKS
}

\author{
Huan Liang 1, 2, a, Cheng Yang ${ }^{1, b}$, Zhiquan Pan ${ }^{1,2 * c}$ \\ 1. Wuhan Institute of Technology, National Engineering and Technology Research Center for Development \& Utilization of Phosphorus Resources, \\ Wuhan 430073, China \\ 2. Hubei Research and Design Institute of Chemical Industy, Wuhan 430073, China
}

This is an open access article distributed under the Creative Commons Attribution License, which permits unrestricted use, distribution, and reproduction in any medium, provided the original work is properly cited

\section{ARTICLE DETAILS}

\section{Article History:}

Received 02 october 2017

Accepted 06 october 2017

Available online 11 october 2017

Keywords:

phosphate rocks, apatie, dolomite, sulfo fatty acid, flotation

\section{ABSTRACT}

\begin{abstract}
We designed and synthesized a novel sulfo fatty acid (SSA) which demonstrated high selectivity and strong collecting capacity for the beneficiation of phosphate ore by reverse flotation. The SSA collector was investigated to float single minerals and real phosphate ore. The collecting performance on minerals was interpreted by means of adsorption amount measurement, zeta potential measurement, scanning electron microscopy (SEM) and energy dispersive X-ray spectroscopy (EDX) analysis. The appropriate $\mathrm{pH}$ value for the single minerals flotation was close to $\mathrm{pH} 5$ at which dolomite presents quite good floatability while apatite exhibit very poor floatability. The performance of SSA and oleic acid used for the real phosphate ore flotation was compared, and the critical factors of phosphate ore flotation were investigated. It was found that the novel SSA achieved superior results, causing dolomite adsorbing reagent in larger amount than apatite.
\end{abstract}

\section{INTRODUCTION}

Phosphate rocks are vital nonrenewable resources and are essential components in agricultural fertilizers and phosphorous-based chemicals. About $95 \%$ of the phosphate produced as a raw material is consumed in the fertilizer industry. A large proportion of the world's phosphate reserves are sedimentary deposits containing a considerable amount of carbonate minerals, which cannot satisfy the industrial requirements for phosphates to produce superphosphates and phosphoric acid [1]. Although many measures were investigated for beneficiating phosphate minerals, flotation is energy saving and low cost in alumina production. However, the carbonated sedimentary phosphate ores are extremely difficult to concentrate via flotation due to the similar physicochemical surfaces properties of the main constituents, carbonate and phosphate minerals [2]. The processing of carbonated sedimentary phosphate still represents a continuous industrial worldwide challenge.

Although the carbonated sedimentary phosphate process had been implemented, on a commercial scale for several decades, yet there is a lot of discrepancy about the best strategy to achieve selectivity. All the constituents of the carbonated sedimentary phosphate ores react in a nearly identical manner as regards the collectors, particularly the traditional fatty acids [3]. No matter which flotation approach is used, flotation collectors are critical to the magnesium-removal. The reported collectors for flotation of carbonates minerals were carboxylate types, involving stearic acid, oleic acid, linoleic acid and their salts. Oleic acid, as a kind of traditional collector, has been widely applied in the magnesiumremoval practice, but its poor selectivity has resulted in low phosphorite recovery for an acceptable phosphorated concentrate [4]. Therefore, it is very significant to design and synthesize a new type of functional groups of reagents.

In our previous work, a novel reagent sulfo fatty acid had been synthesized for the flotation separation of carbonates minerals from phosphorite, which exhibited better selectivity than traditional acids. However, it did not have strong collecting capacity for carbonates minerals. The present work focuses on multifunctional collectors with high selectivity and strong collecting capacity for the flotation of carbonates against phosphate rocks. Its collecting performance was investigated by flotation tests of single minerals and real minerals. The interaction between collector and minerals was also investigated via adsorption amount, zeta potential, SEM and EDX analysis.

\section{Experimental}

\subsection{Synthesis of collector}

Sulfo fatty acid compounds were synthesized referring to unit reaction [5], and their synthetic mechanism were furnished in Fig. 1. All chemicals for synthesis are analytical grade reagents and were purchased from China National Pharmaceutical Group Corporation. Infrared spectrometer (Nicolet, 6700, USA) was applied to identify the structure of synthesized products. The $100 \mathrm{~mL}$ solution was prepared by slow addition of chlorosulfonic acid into a vigorously stirred absolute ethanol solution of stearic acid while refluxing for $6 \mathrm{~h}$ at $85^{\circ} \mathrm{C}$ until the molar ratio of [stearic acid]: [chlorosulfonic acid] reached 1: 1.2 . The reaction crude product was purified by the mixture of water and acetone (volume ratio $1: 2$ ) at $60{ }^{\circ} \mathrm{C}$, and cooled until a large number of crystal was separated out. The product was then filtered, washed by centrifugation at $5000 \mathrm{rpm}$ for $10 \mathrm{~min}$ with de-ionized water for several times, dried at room temperature. Finally, $\alpha-$ sulfo stearic acid (SSA) was obtained.
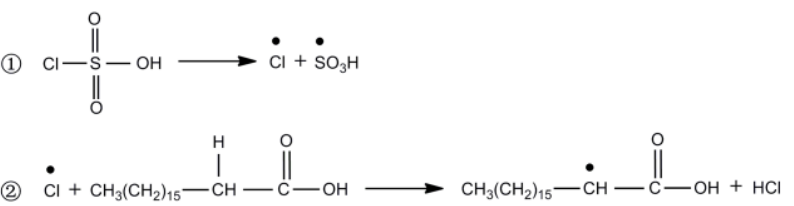

(3) $\mathrm{CH}_{3}\left(\mathrm{CH}_{2}\right)_{15}-\dot{\mathrm{CH}}-\stackrel{\mathrm{O}}{\|}-\mathrm{OH}+\dot{\mathrm{SO}}_{3} \mathrm{H} \longrightarrow \mathrm{CH}_{3}\left(\mathrm{CH}_{2}\right)_{15}-\stackrel{\mathrm{CH}}{\mathrm{SO}_{3} \mathrm{H}} \|_{\mathrm{C}}^{\mathrm{O}}-\mathrm{OH}$

Fig. 1: The chemical reaction formula of sulfo fatty acid.

\subsection{Flotation test}

2.2.1 Flotation test for single minerals 
Single minerals containing apatite, and dolomite were collected from Guangdong province in China. All the minerals samples were handpicked and ground in porcelain mill for $1 \mathrm{~min}$ at every turn to pass a $0.074 \mathrm{~mm}$ sieve. The purities of the minerals were identified at least $90 \%$ by measuring mineral constituents of single minerals samples with X-ray diffractometer (Bruker, D8, Germany).

Flotation tests of single minerals were performed in flotation machine (Rock, XFG-35, China) with $35 \mathrm{ml}$ effective cell volume, and the impeller speed was fixed at $1650 \mathrm{rpm}$. Mineral samples $(2 \mathrm{~g})$ were placed into the flotation cell, and decent amount of distilled water were added and stirred for $5 \mathrm{~min}$. The $\mathrm{pH}$ of the mineral suspension was adjusted to a desired value using 10 wt.\% sulfuric acid or sodium carbonate solution. After adding the desired amount of collector solution, the suspension was agitated for $2 \mathrm{~min}$, and then the flotation was carried out for $4 \mathrm{~min}$. The floated and unfloated fraction were separately dried and weighed for calculating the recovery. The average value in three flotation tests under the same condition was used as the recovery of single minerals.

\subsubsection{Flotation test for real minerals}

Real phosphorus ore from Sichuan province in China were crushed to -3 $\mathrm{mm}$. Based on the X-ray diffraction (XRD) analysis, the composition of the phosphorus ore were apatite, dolomite, and quartz. The chemical compositions of the phosphorus ore by chemical assay were given in Table 1.

\begin{tabular}{llll}
\hline Element & Conc. (wt.\%) & Element & Conc. (wt.\%) \\
\hline $\mathbf{P}_{2} \mathbf{O}_{5}$ & $\mathbf{2 4 . 4 7}$ & $\mathrm{SiO}_{2}$ & 9.25 \\
$\mathrm{MgO}$ & 5.62 & $\mathrm{SO}_{3}$ & 0.33 \\
$\mathrm{CaO}$ & 34.04 & $\mathrm{CuO}$ & 0.01 \\
$\mathrm{Fe}_{2} \mathrm{O}_{3}$ & 0.32 & $\mathrm{PbO}$ & 0.01 \\
$\mathrm{Na}_{2} \mathrm{O}$ & 0.07 & $\mathrm{SrO}$ & 0.08 \\
$\mathrm{~K}_{2} \mathrm{O}$ & 0.11 & $\mathrm{~F}$ & 6.40 \\
$\mathrm{Al}_{2} \mathrm{O}_{3}$ & 0.65 & $\mathrm{Cl}$ & 0.02 \\
$\mathrm{MnO}$ & 0.04 & $\mathrm{CO}_{2}$ & 18.58 \\
\hline
\end{tabular}

Table 1: X-ray fluorescence analysis of phosphorus ore

Flotation tests of phosphorus ore were carried out to investigate collecting performance of the novel synthesized sulfo fatty acid compound. The ore samples $(500 \mathrm{~g})$ were ground to $82 \%$ passing $0.074 \mathrm{~mm}$. The pulp was conditioned at $25 \mathrm{wt} . \%$ solids in an XFD laboratory flotation cell with a volume of $0.75 \mathrm{~L}$ for $3 \mathrm{~min}$ and the impeller speed was fixed at $2000 \mathrm{rpm}$. Analytical grade reagents sulfuric acid solution were used as a $\mathrm{pH}$ regulator by adjusting the pulp $\mathrm{pH}$ to a desired value and was conditioned for $10 \mathrm{~min}$. Phosphoric acid was used as a depressant and conditioned for $5 \mathrm{~min}$, after which the slurry was conditioned with collectors for $5 \mathrm{~min}$. The tailing (floated fraction) and concentrate (unfloated fraction) were separately dried and weighed to calculate the yield, and separately sampled to analyze the contents and the recovery of $\mathrm{P}_{2} \mathrm{O}_{5}$ and $\mathrm{MgO}$.

\subsection{Measurement of adsorption}

Mineral samples $(2.0 \mathrm{~g})$ were added to an aqueous solution $(40 \mathrm{ml})$ with the desired $\mathrm{pH}$ value that was prepared with $0.01 \mathrm{~mol} / \mathrm{L}$ sulfuric acid solution or $0.01 \mathrm{~mol} / \mathrm{L}$ sodium carbonate solution. After the desired amount of collector solution was added, the suspension was agitated at 25 ${ }^{\circ} \mathrm{C}$ for $30 \mathrm{~min}$. The conditioned pulp was centrifuged at $2000 \mathrm{rpm}$ for 10 min, and the equilibrated solution was immediately gathered to analyze the concentration of the collector by a UV spectrophotometer (Shimadzu, model UV 1601, Japan). The average value in three measurements under the same condition was used as adsorption amount.

\subsection{SEM-EDX}

SEM-EDX was used to observe the adsorption of the novel collector onto single minerals. After adsorption, the samples were thoroughly washed with deionized water of the same $\mathrm{pH}$ to remove loosely attached composition. Before observation, the floated fractions were dried in an oven at $60{ }^{\circ} \mathrm{C}$ and gold coated under vacuum using an ion coater. Images were acquired using a Hitach SU8010 field emission scanning electron microscope.

\subsection{Zeta potential measurements}

Zeta potential was measured with zeta potential analyzer (Brookhaven, Zetaplus, USA). The suspension containing $0.01 \%$ single minerals by weight less than $5 \mu \mathrm{m}$ was dispersed in a beaker for 15 min with the use of $1.0 \times 10^{-2} \mathrm{~mol} / \mathrm{L} \mathrm{NaOH}$ and $\mathrm{HCl}$ solution as a $\mathrm{pH}$ regulator. After measuring the $\mathrm{pH}$, collectors at a concentration of $2.0 \times 10^{-4} \mathrm{~mol} / \mathrm{L}$ were added while stirring on a magnetic stirrer for $3 \mathrm{~min}$. The suspension was immediately transferred to the tested square sample vessel for the measurement of the zeta potential. The experiments were carried out at room temperature $\left(20^{\circ} \mathrm{C}\right)$. Three independent suspensions were prepared in the same condition and measured to obtain the average value of the zeta potential.

\section{Results and discussion}

\subsection{Design and synthesis of collector}

FT-IR spectroscopy was used to investigate the chemical structure of the collector sulfo stearic acid. Using chlorosulfonic acid as a sulfonating agent, the collector was successfully synthesized. The structure of SSA and oleic acid was confirmed by the presence of the characteristic absorption in infrared spectrum (Fig. 2). For stearic acid, IR ( $\mathrm{KBr}$ pellet, $\left.\mathrm{cm}^{-1}\right): 2920$ $\left(-\mathrm{CH}_{2}\right), 1726(\mathrm{C}=\mathrm{O}$ in $-\mathrm{COOH})$. For SSA, IR ( $\mathrm{KBr}$ pellet, $\left.\mathrm{cm}^{-1}\right): 2920\left(-\mathrm{CH}_{2}\right)$, $1726(\mathrm{C}=0$ in $-\mathrm{COOH}), 1220\left(-\mathrm{S}-\mathrm{O}\right.$ in $\left.-\mathrm{SO}_{3}\right), 719(\mathrm{C}-\mathrm{S})$, and $661(\mathrm{~S}=0 \mathrm{in}-$ $\mathrm{SO}_{3}$ ).The result of FTIR spectrum presented that the synthesized compound corresponds with the designed collector.

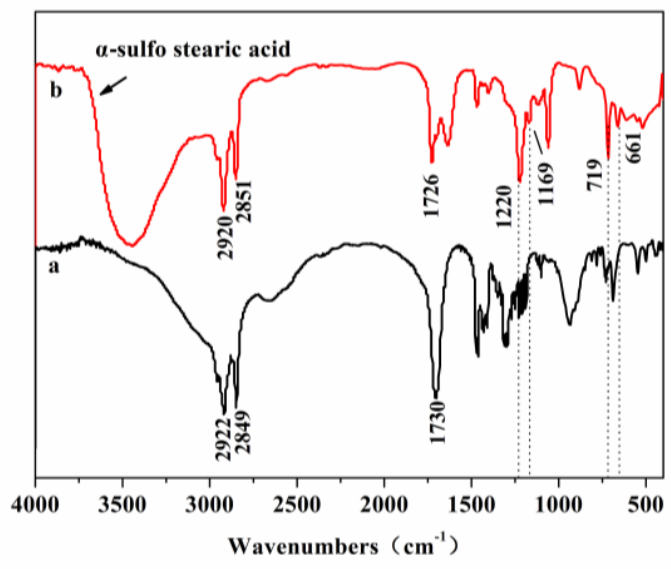

Fig. 2: The FTIR spectra of (a) SSA and (b) stearic acid.

\subsection{Collecting performance of collector}

\subsubsection{Performance for single minerals}

Fig. 3 presented the flotation response of single minerals as a function of $\mathrm{pH}$ value in the presence of $5 \times 10^{-5} \mathrm{~mol} / \mathrm{L}$ SSA and oleic acid as collectors. It was shown that the dolomite exhibited good floatability around acidic $\mathrm{pH}$ values. Both collectors present stronger collecting capacity to dolomite than that to apatite. Moreover, oleic acid had a strong collecting power for the single minerals but its selectivity for flotation was very limited, only about $46.57 \%$ of the flotation recovery difference value was obtained. In terms of the flotation system with SSA data on the flotation recovery indicated that the minerals separation ability of collectors tested was in the following sequence: SSA > oleic acid, almost about $60 \%$ of the flotation recovery difference value.

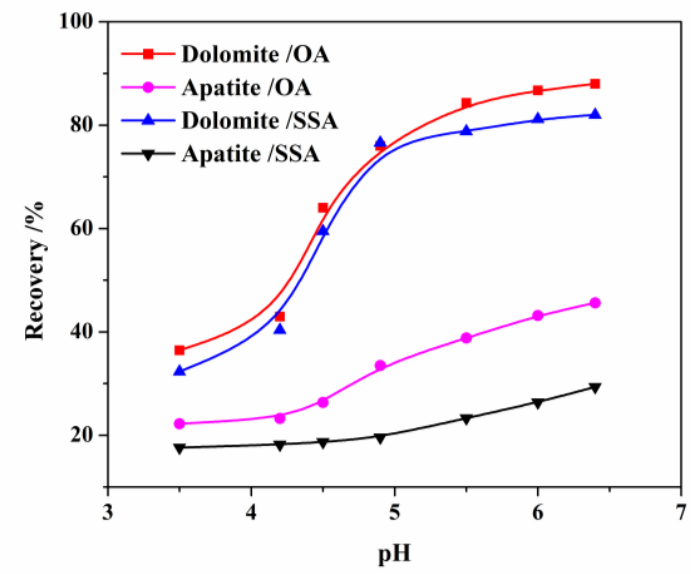

Fig. 3: Flotation recovery of the single minerals as a function of $\mathrm{pH}$ value 
in the presence of $5 \times 10^{-5} \mathrm{~mol} / \mathrm{L}$ collectors.

Fig. 4 demonstrated the flotation response of single minerals as a function of reagent concentrate at $\mathrm{pH} 5$. Increasing their concentrate improved the flotation recovery of minerals. At concentrate of $7 \times 10^{-5} \mathrm{~mol} / \mathrm{L} \mathrm{SSA}$, the floated dolomite got almost up to $100 \%$; but apatite also showed good floatability as the flotation recovery was more than $50 \%$. For the minerals separation ability of dolomite and apatite, the efficiency of the collectors was in descending order of SSA followed by oleic acid.

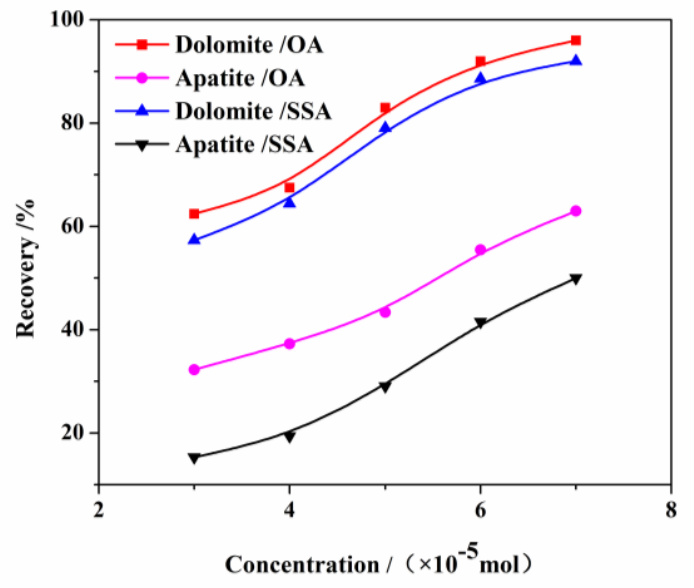

Fig. 4 Flotation recovery of the single minerals as a function of collectors concentrate at $\mathrm{pH} 5$.

\subsubsection{Performance for real minerals}

SSA presented excellent difference in the floatability of dolomite and apatite minerals at $\mathrm{pH} 5$ as shown above, but, its collecting capacity for dolomite for flotation was not strong. In order to achieve strong collecting capacity and high selectivity, SSA and oleic acid were combined into multifunctional collector by the optimum proportion. Table 2 presented the results of the flotation separation of real phosphate rocks using SSA or oleic acid as collectors under its optimized conditions. The results showed that the beneficiation of phosphate rocks by selective flotation could be accomplished using SSA. The concentrate assaying over $32 \% \mathrm{P}_{2} \mathrm{O}_{5}$ at a recovery of $90.40 \%$ could be floated, while the content of $\mathrm{MgO}$ was reduced to $0.94 \%$. Although, the flotation recovery and content of $\mathrm{P}_{2} \mathrm{O}_{5}$ in the phosphate concentrate was roughly the same, the content of $\mathrm{MgO}$ was remain $2.02 \%$ using oleic acid as collector. Therefore, the selectivity of SSA was obviously better than that of oleic acid.

\subsection{Collector adsorption on mineral}

The adsorption amount of SSA on the dolomite and apatite minerals in the presence of $5.0 \times 10^{-5} \mathrm{~mol} / \mathrm{L}$ collector was shown in Fig. 5 . The adsorption amount presented almost the same variance trend as it rised with the increase of pulp $\mathrm{pH}$ value in range of 3-7. The optimum condition for the highest adsorption amount gets close to the $\mathrm{pH}$ value about 5 , at which dolomite adsorbed much more than apatite. The result was quite in accordance with the observed flotation recovery shown in Fig. 3.

\begin{tabular}{lllllll}
\hline \multirow{2}{*}{ Products } & Yield & \multicolumn{2}{c}{ Content (\%) } & \multicolumn{2}{l}{ Recovery (\%) } & Conditions \\
\cline { 3 - 6 } & $(\%)$ & $\mathrm{P}_{2} \mathrm{O}_{5}$ & $\mathrm{MgO}$ & $\mathrm{P}_{2} \mathrm{O}_{5}$ & $\mathrm{MgO}$ & (g/ton) \\
\hline Concentrate & 68.31 & 32.37 & 0.94 & 90.40 & 11.42 & SSA: 960 \\
Concentrate & 63.77 & 32.25 & 1.67 & 84.05 & 18.95 & $\begin{array}{l}\text { oleic acid: } \\
\text { 960 }\end{array}$ \\
\hline
\end{tabular}

Table 2: The flotation results of phosphate ore using SSA as collector comparing with oleic acid as collector

apatite in the zeta potential decreased. By comparison, the introduction of collector caused dolomite much more negative than apatie, also showing and confirming that SSA was in larger amount on dolomite than on apatite minerals.

The zeta potential of minerals under collector becomes more negative was associated with the compositions of both collectors and dolomite/water interface under different $\mathrm{pH}$ value. Since pKa of carboxyl $(-\mathrm{COOH})$ and sulfo $\left(-\mathrm{HSO}_{3}\right)$ was around 4.6 and 7.2 respectively, the polar group in SSA mainly registered as neutral carboxyl $(-\mathrm{COOH})$ at $\mathrm{pH}<4.6$, carboxyl anion $\left(-\mathrm{COO}^{-}\right)$at $\mathrm{pH}>4.6$, neutral sulfo $\left(-\mathrm{HSO}_{3}\right)$ at $\mathrm{pH}<7.2$ and hydroxycarbamoyl anion $\left(-\mathrm{SO}_{3}-\right)$ at $\mathrm{pH}>7.2$. When the collector was introduced into the pulp under different $\mathrm{pH}$ values, its species in more negative charge possibly replaced $\mathrm{OH}_{2}, \mathrm{OH}^{-}$or $\mathrm{O}^{2-}$ in the dolomite/ water interface, thus resulting in the zeta potential of the minerals declined. Since the adsorption amount of SSA was much more on dolomite than on apatite, which was easy to understand that dolomite became much more negative than that of apatite after treated by SSA.

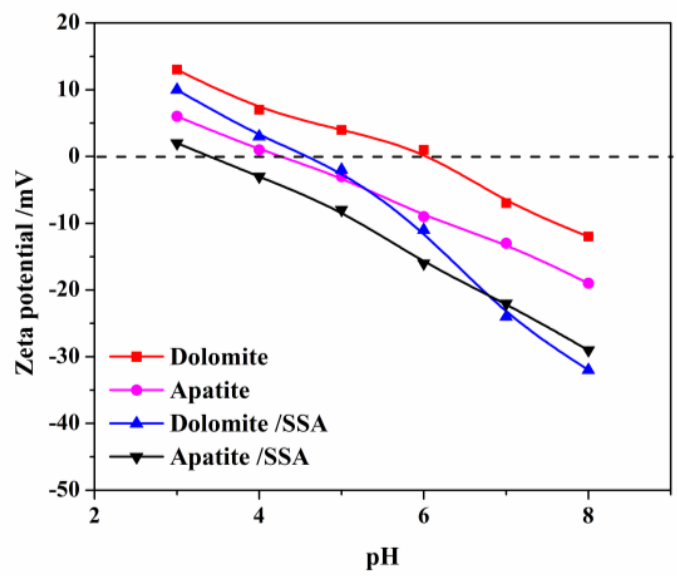

Fig. 6: Relationship between zeta potential of minerals and pulp pH value without or with $5 \times 10^{-5} \mathrm{~mol} / \mathrm{L}$ SSA.

\subsection{SEM images and EDX analysis}

SEM coupled with EDX was used to obtain a general idea of the flotation tests separation efficiency and to evaluate particle composition and liberation. The data might provide some insight to the collector interaction with single minerals. Micrographs of dolomite and apatite with the collector adsorbed at the optimal conditions of pH 5 and $2.0 \times 10^{-4} \mathrm{~mol} / \mathrm{L}$ SSA were shown in Fig. 7. The data presented in Fig. 7a and Fig. 7c inferred that SSA covered the whole surface of dolomite, as expected, while dolomite particles contained much $\mathrm{C}$ and $\mathrm{S}$ elements through the EDX analysis. The individual dolomite particles were transformed into hydrophobic agglomerates through the interaction with the SSA, which enhanced the floatability of dolomite. However, SSA was sparse in the region of apatite particles, and apatite particles contained little C and S elements by the EDX scanning, as shown in Fig. 7b and Fig. 7d. It also indicated SSA could be the excellent collector for separation of dolomite from phosphate ore.
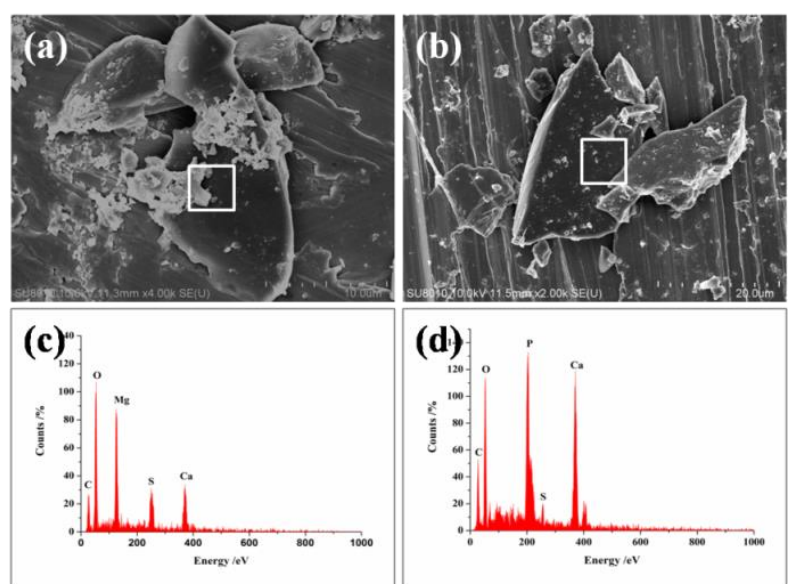

Fig. 7: SEM images showed the adsorption of the collector on the single minerals: (a) dolomite, (b) apatite, (c) EDX analysis of dolomite, (d) EDX analysis of apatite.

\section{Conclusions}

Implanted the sulfo group into stearic acid, the novel sulfo fatty acid was designed and synthesized as collector. The results from the flotation tests of single minerals showed that SSA presented the stronger collecting capacity to dolomite than that to apatite. When SSA was used as the collector, the flotation recovery of dolomite and apatite were $80.25 \%$ and $21.77 \%$ respectively, almost about $60 \%$ of the flotation recovery difference value was obtained. Therefore, SSA exhibited high selectivity due to the appropriate acid dissociation constant of sulfo group. The flotation performance of SSA was examined by comparison with the traditional collector oleic acid. The results showed that SSA for flotation 
separation of dolomite against phosphate rocks was obviously better than that of oleic acid.

The synthesis of SSA was of short process and relatively high yield. The collector SSA is highly selective in separating dolomite from phosphate ore and might supply qualified flotation concentrate for fine phosphorous chemical engineering industry (low content of $\mathrm{MgO}$ ). Therefore, SSA was perhaps suitable for reverse flotation phosphate ore with a potential prospect.

\section{Acknowledgements}

This work was financially supported by the Science and Technology Department of Hubei Province (2015ACA057), for which the authors wish to express our great appreciation.

\section{References}

[1] M. Mohammadkhani, M. Noaparast, S.Z. Shafaei, et al. Double reverse flotation of a very low grade sedimentary phosphate rock rich in carbonate and silicate. International Journal of Mineral Processing, 100 (2011), p. 157-165.
[2] T.R. Boulos, A. Yehia, S.S. Ibrahim, et al. A modification in the flotation process of a calcareous-siliceous phosphorite that might improve the process economics. Minerals Engineering, 69 (2014), p. 97-101.

[3] M.I. Al-Wakeel, C.L. Lin, J.D. Miller. Significance of liberation characteristics in the fatty acid flotation of Florida phosphate rock. Minerals Engineering, 22 (2009), p. 244-253.

[4] Y.R. Jiang, X.X. Li, R Feng, et al. Jun-Chuan Li. Novel alkyl bis(hydroxycarbamoyl) propionic acids for flotation separation of diaspore against aluminosilicate minerals. Separation and Purification Technology, 87 (2012), p. 135-141.

[5] D.D. Song, X.L. Sun, F.Y. Liu. Preparation and properties of a sulfonic acid series gemini surfactants. China Surfactant Detergent \& Cosmetics , 42 (2012), p. 428-431.

[6] F. Zhou, C.J. Yan, H.Q. Wang, et al. Flotation behavior of four C18 hydroxamic acids as collectors of rhodochrosite. Minerals Engineering, 78 (2015), p. 15-20. 